\title{
A Review on the Addictive Materials Paan Masala (Paan Parag) and Nass (Naswar)
}

\author{
Tayebeh Nakhaei Moghaddam ${ }^{\mathrm{a}^{*}}$, Faramarz Mobaraki ${ }^{\mathrm{b}}$, \\ Mohammad Reza Darvish Moghaddam ${ }^{c}$, Maryam Jafardokht Bonjar ${ }^{d}$ \\ ${ }^{a}$ Senior Expert in the Food Science and Industry Department, Food and Medicine Expert, Iranshahr University of Medical Sciences, Iranshar, Iran. \\ ${ }^{b}$ General Practitioner, Chabahar Health Center, Iranshahr University of Medical Sciences, Iranshahr, Iran. \\ ${ }^{c} 115$ Emergency Worker, Iranshahr University of Medical Sciences, Iranshar, Iran. \\ ${ }^{d}$ Teacher, Esmat Primary School, Chabahar Education and Training, Sistan and Baluchestan Provincial Office of Education, Zahedan, Iran .
}

Received 10 February 2019; Accepted 12 May 2019

\begin{abstract}
There are many reasons why people use addictive substances including the euphoric and stimulating effects they have. This article introduces the addictive substances Paan, Naswar, nicotine, and other related products. It also deals with their use by people who are not aware of their addictive properties and use them for their side effects as mouth freshener and tasty and fragrant snacks. Furthermore, they are marketed in beautiful and attractive packages for various age groups, even children and adolescents (who inadvertently use them, without being aware of their effects and over time become addicted to them). Therefore, providing information to, and constant education of, target groups can be effective in improving the public health.
\end{abstract}

Keywords: Addiction; Paan; Nicotine; Nass; Naswar.

\section{Introduction}

Nowadays, the term addiction refers to chronic diseases that give the patients a strong unhealthy motivation to engage in specific activities [1]. Forming a habit and getting used to and dedicating oneself to a reproachable habit is considered addiction. In other words, becoming a slave to a narcotic that is considered physically or socially harmful is called addition. The term addiction cannot be easily defined and its consequences manifest themselves in different ways such as tolerance of the body to, and its dependence on, addictive substances.

In modern medicine, the word substance dependence is used instead of addition because it has the same meaning but is more accurate and more correct. Substance dependence means that the person becomes physically and psychologically dependent on a chemical material so that, when it is used, it gives a feeling of tranquility and joy, and when it is not used, the person experiences a hangover, physical pains, and discomfort. Physical dependence is the state a person is in after repeated use of a specific substance so that, when it is not used (or it loses its effect), the person experiences violent physical disorders such as leg pain, runny nose, severe bone pain, restlessness, nausea, etc. Psychological dependence refers to the desire for repeating the experience of feeling the euphoria resulting from substance abuse. In other words, the person gets satisfaction from using narcotic. This feeling of satisfaction makes the person inclined to repeat the experience, which will lead to repeating the use of the substance when the person feels discomfort to get over this feeling. In this type of dependence, the person becomes dependent not only on the

* Corresponding author: nakhaei.moqaddam@gmail.com

doi) http://dx.doi.org/10.28991/SciMedJ-2019-0102-4

$>$ This is an open access article under the CC-BY license (https://creativecommons.org/licenses/by/4.0/).

(C) Authors retain all copyrights. 
substance but also on the environmental conditions and specific mannerisms of addicts.

The tolerance phenomenon is the adaptation of the person to the used substance, which manifests itself by reduced bodily response to the use of the substance and to a specific dose of it. Consequently, if the person wishes to experience the same feelings, a higher dose of the substance must be used [2].

Trade in narcotics and addictive substances, with a yearly turnover of over 2000 billion dollars, is one of the most profitable global trades. Obviously, people engaged in this trade including smugglers continuously employ new methods such as changing the types of narcotics and the ways they are used to enjoy a greater share of the market. Therefore, nowadays, we witness the marketing of various addictive substances, some with tempting names, especially for the youths and adolescents. This necessitates greater familiarity of people in the society, especially parents and teachers, with these substances and with their side effects [3]. Tobacco use is one of the main factors causing oral cavity and pharynx cancers [4].

\section{Some Addictive Substances, the Reasons They are Used, and Their Side Effects}

\subsection{Nass or Naswar}

Mixtures of tobacco powder and lime have been used for a long time in our neighboring countries on the east (Afghanistan and Pakistan) [5], and to a lesser extent among some people in the east and southeast of our country. Nass, or Naswar, is a green powder with a bad and nauseous odor packaged and sold in small plastic bags. The user puts the powder itself, or the powder wrapped in tissue paper, under the lower lip and, after getting the euphoric feeling, spits it out [3]. Profit mongers and producers and distributors of Naswar add pleasant smelling essential oils and artificial sweeteners such as sodium saccharine [5] to the produced powder, place the mixture in small bags that look like tea bags, put a number of these small bags in a beautiful package, and market the product under various names. In recent decades, tobacco use has increased in the Middle East, especially among the youths and adolescents [6].

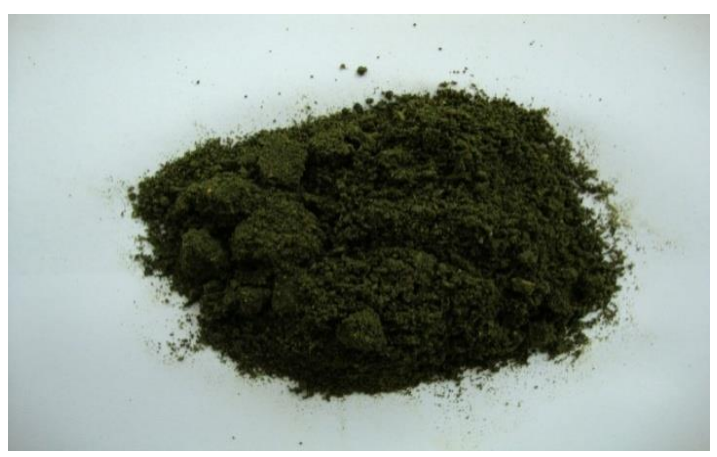

Figure 1. Traditional Nass or Naswar powder

\subsubsection{Reasons for using Nass or Naswar}

The simple kinds of Nass or Naswar are only used for their stimulating or euphoric effects. However, some people, especially among the youth, use the new types of Naswar (pictures of some of which are shown in Figure 2) as breath fresheners also; or, they deceive themselves by pretending they use these products as breath fresheners while in fact they are after enjoying their euphoric effects.

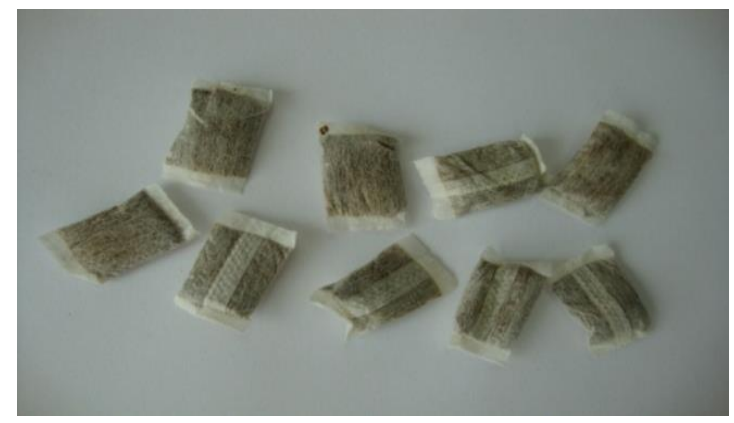

Figure 2. Small fragrant Naswar bags ready for use

\subsubsection{Harmful Effects of Various Kinds of Nass or Naswar}

The most harmful compound in Nass or Naswar is nicotine, which is present in tobacco, is absorbed by oral mucosa, and enters the blood stream. Besides nicotine, Nass includes lime powder that increases nicotine entry into 
the blood stream through severely corroding the gums and oral tissues [7]. Nicotine is a toxic alkaloid, and lethal, if taken at the dose of $0.1 \mathrm{~g}(60-100 \mathrm{mg})$. The main side effects of smoking are caused by nicotine and these side effects, due to their importance, will be explained at the end of this section.

The lime in Naswar severely damages oral tissues because of its corrosive effect, and causes caries and gum lesions that finally lead to infections. Repeated irritation of oral tissues by lime is one of the causes of oral cavity cancer. Absorption of nicotine and other toxins and pollutants by damaged oral tissues also increases greatly. Spitting out Nass remnants from the mouth by the user results in possible transmission of microbial and viral infections into the environment, and is especially effective in spreading respiratory diseases [3]. Moreover, this waste may be polluted with variouses and heavy metals such as lead and toxic substances including arsenic [7].

\subsection{Effects and Side Effects of Nicotine}

Nicotine is a toxic chemical used in many pesticides [3]. It is an addictive factor [8, 9] and many of its psychological properties result from nicotine. Use of tobacco, especially oral use (as in the case of Naswar, for example) causes rapid release of adrenaline from the cortex of adrenal glands, which is accompanied by symptoms such as increased heart rate, high blood pressure, and quick breathing. Adrenaline increases blood sugar, and nicotine itself has inhibitory effects on insulin secretion, both of which effects raise blood sugar level. Therefore, the person feels less hungry or, in other words, has a decreased appetite. Nicotine also slightly raises the basal metabolic rate and, hence, the body burns more calories, and it raises blood LDL levels, which will increase incidence of atherosclerotic diseases. Increased levels of blood LDL, together with high blood pressure [10], play an important role in the development of cardiovascular diseases caused by nicotine [11]. Less than 10 seconds after entering the blood stream, nicotine reaches the brain where it stimulates brain cholinergic receptors to release more acetylcholine into the brain [12]. Some of the symptoms of nicotine toxicity are related to the hyperactivity of cholinergic nerves and include increased salivary secretion, diarrhea, nausea, abdominal pain, labored breathing, and sweating. Stimulation of brain cholinergic neurons increases dopamine release in the reward pathway and causes euphoria, which is what induces the person to use the narcotic again. Another effect of nicotine is the release of glutamate, a neurotransmitter involved in learning and in memory. Glutamate increases connections between neuronal groups. The brain, in the presence of nicotine, releases more endomorphine in response to stimulants. Low dosages of nicotine stimulate the autonomous neuroganglia, while its high dosages suppress them [13].

\subsection{Areca Nut}

Areca nuts are the seeds of areca palms (Areca catechu) that are used after being sliced or ground up or split, and are mixed with materials such as lime, tobacco powder, cinnamon, betel leaf, etc. The three main alkaloids present in areca nuts (arecoline, arecaine, and guvacine) have mild stimulating and euphoric effects and are vasoconstrictors.

Use of areca nuts alone causes oral submucous fibrosis, precancerous lesions, and oral squamous cell carcinoma.

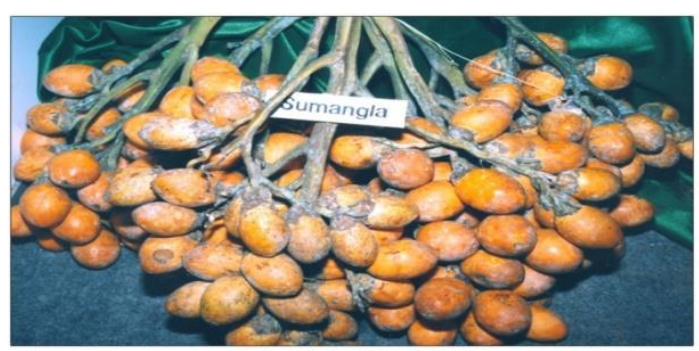

ARECANUT

Figure 3. Areca nuts

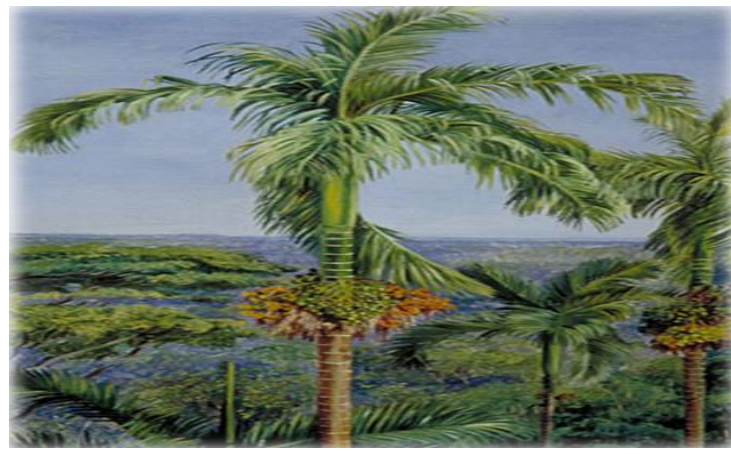

Figure 4. Areca catechu palm trees 


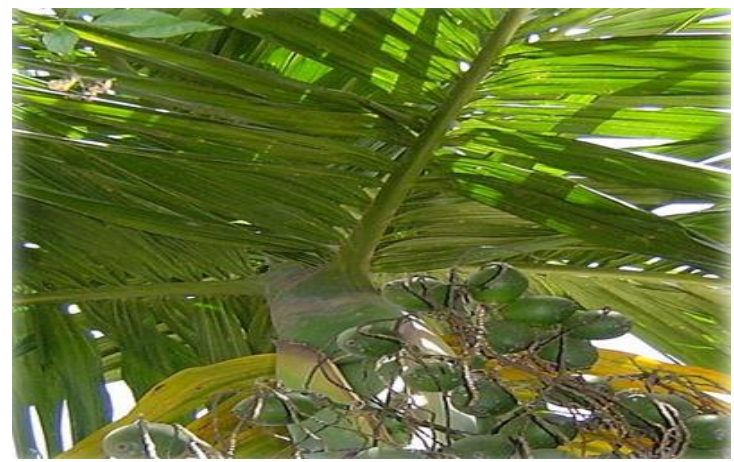

Figure 5. Leaves and fruit of Areca catechu

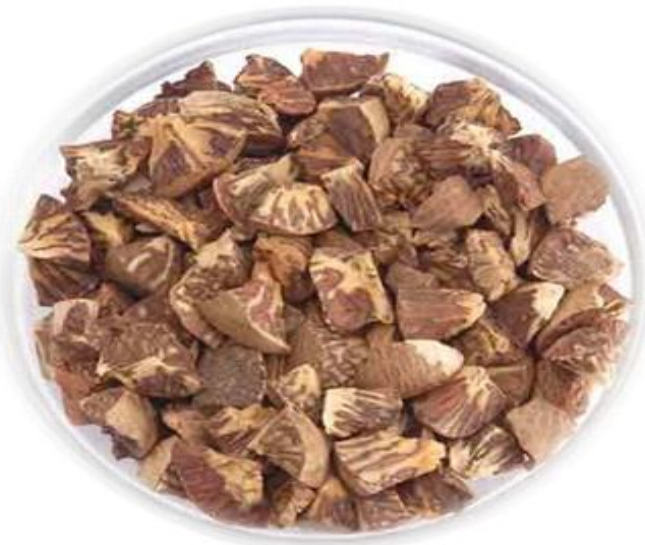

Figure 6. Ground nuts of Areca catechu

Areca catechu trees are wrongly called betel tree, and their seeds are also often mistakenly called betel nuts [14].

\subsection{Betel}

Betel is the leaf a vine (Betel) belonging to the pepper family. Betel leaves are called Paan in the Urdu, Hindi, and Bengali languages. This leaf contains alkylbenzene compounds and has stimulating effects. One way of preparing Paan is to wrap areca nuts in a betel leaf. The combination of areca nut and betel leaf is called Bethlehem. Betel leaves contain eugenol, which is a vasoconstrictor and an antiseptic, and are the fourth addictive material after nicotine, alcohol, and cafeine [15]. Chewing betel nuts is very common in Southeast Asia [16].

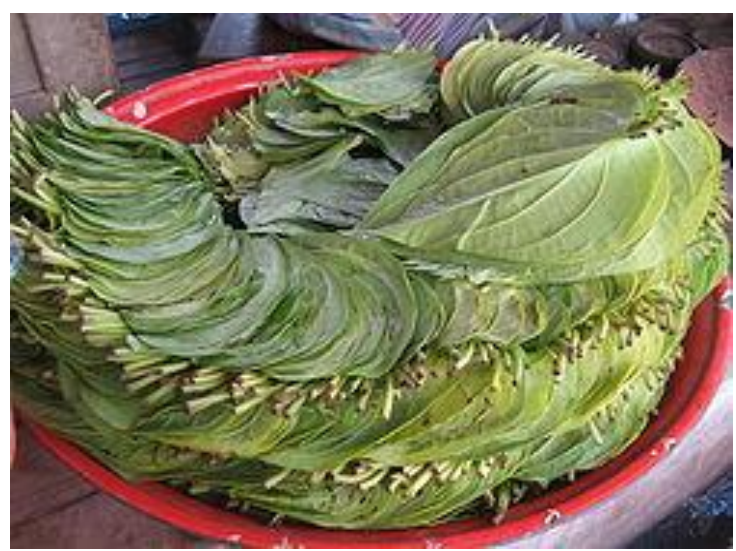

Figure 7. Harvested and ready-for-sale leaves of the plant betel pepper (Piper betle)

Local lesions are formed in the part of the mouth where the substance wrapped in betel leaf is placed repeatedly. The lesions are discoloured and look wrinkled, the mucus becomes thick, and wounds are observed [17]. A unique lesion caused by betel users is shown in Figure 8, which can be reduced by taking lower doses or through changing the place where betel leaf is put in the mouth [18]. 


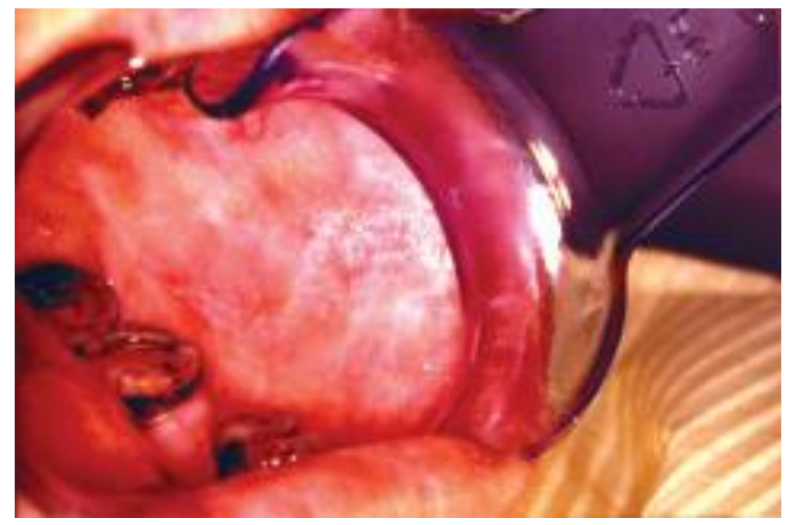

Figure 8. Lesions caused by using betel

Epidemiological studies on oral cavity cancer show a strong link this cancer and using betel, alcohol, or tobacco $[19,20]$. In Taiwan, about $85 \%$ of oral cavity cancer patients had the habit of using betel [21].

\subsection{Catechu}

Catechu (or kata) is a material extracted from Acacia catechu trees and it contains catechol and catecholamine substances. It is a special concentrated liquid prepared from boiling the wood of these trees [22].

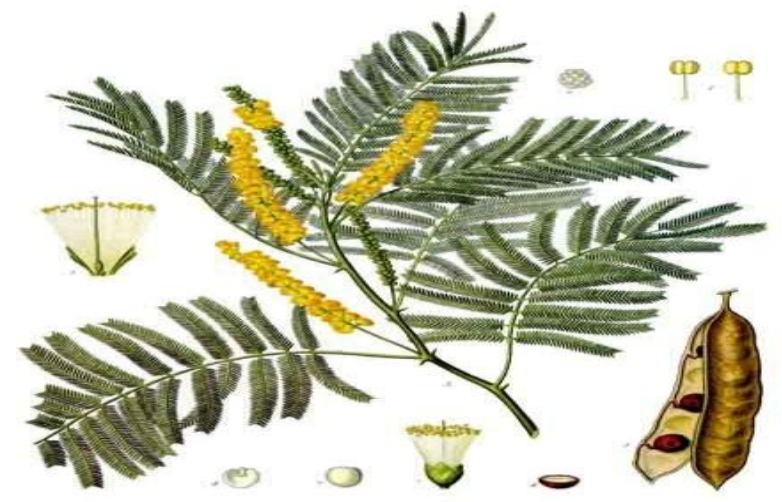

Figure 9. Acacia catech (also called Mimosa catechu)

\subsection{Paan Products}

It must be noted that Paan is not a specific compound, and that it includes various products. In India (the largest consumer of areca nuts) and Pakistan, products containing areca nuts (with or without betel leaf) are usually called Paan. These are available everywhere in ready-to-chew packages named paan masala or supari (Pan Parag is a trade name of one type of Paan Masala or gutka in India).

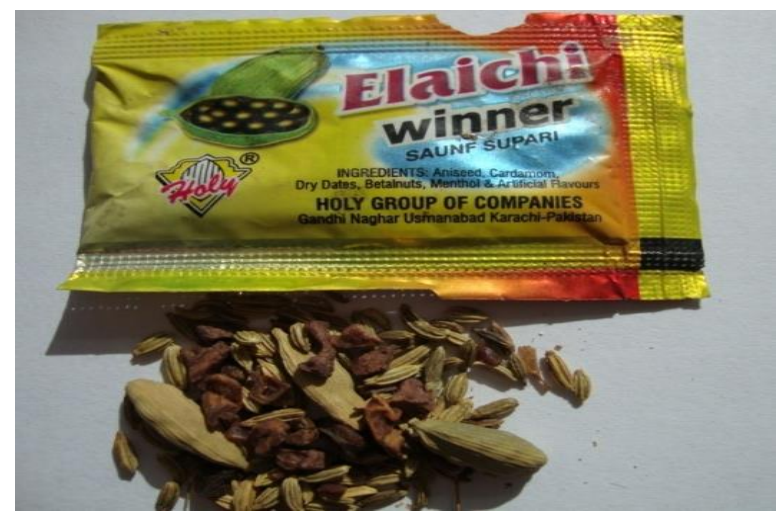

Figure 10. A type of supari that contains cardamom and fennel seeds 


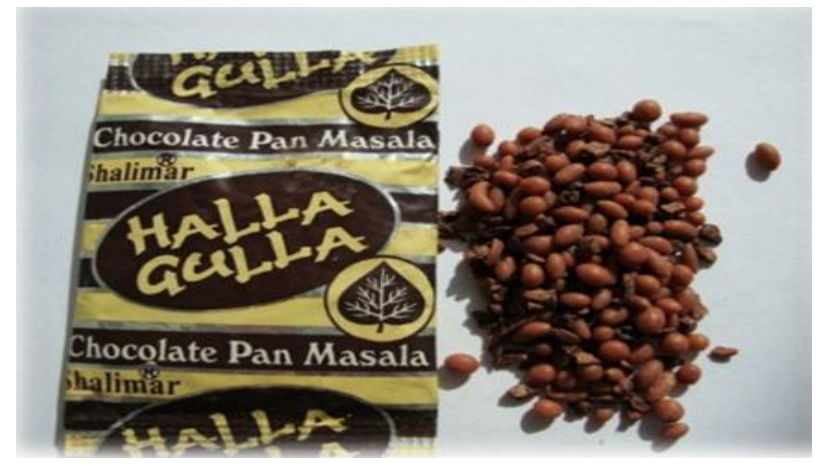

Figure 11. One kind of supari

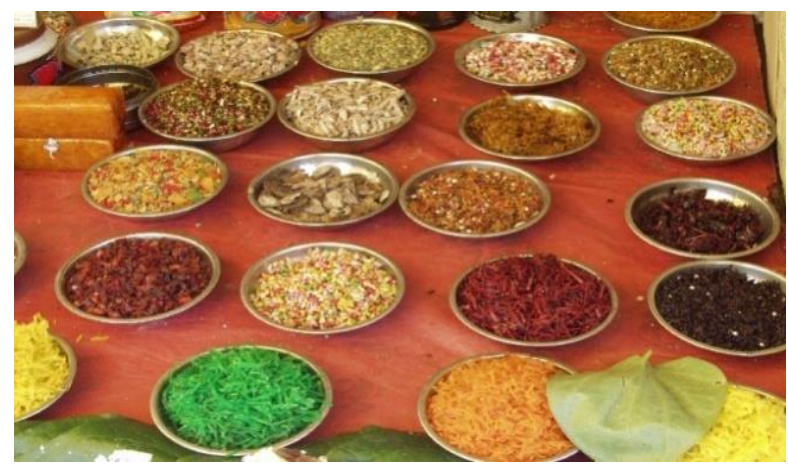

Figure 12. Various materials used in supari

Moreover, a type of areca nuts wrapped in betel leaves is called Paan in South and Southeast Asia, and it is sold in various forms the most common of which are as follows:

Tambaku Paan: Betel leaves filled with tobacco powder and other materials

Pan Masala or plain (sada) paan or supari paan: Betel leaves mixed with ground or sliced areca nuts and other materials

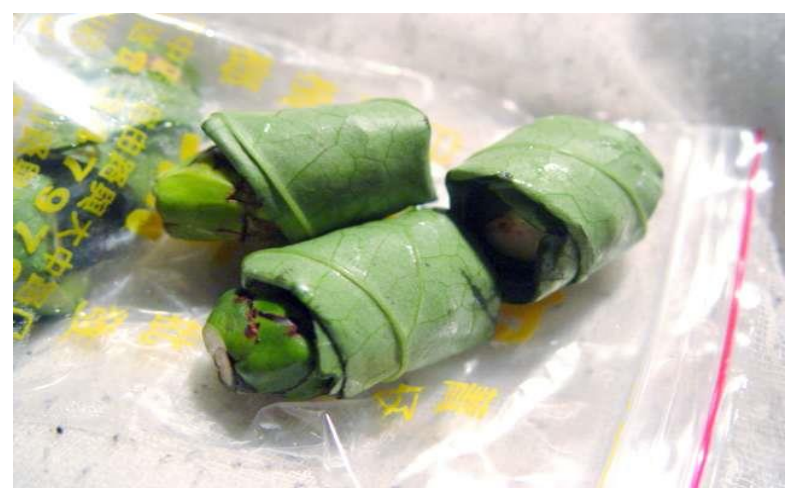

Figure 13. Paan marketed in Taiwan

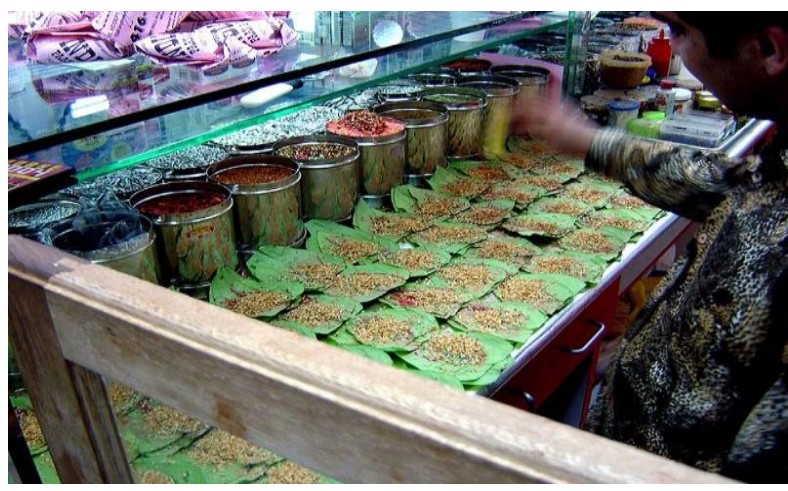

Figure 14. Stand where various kinds of paan are produced and offered for sale 


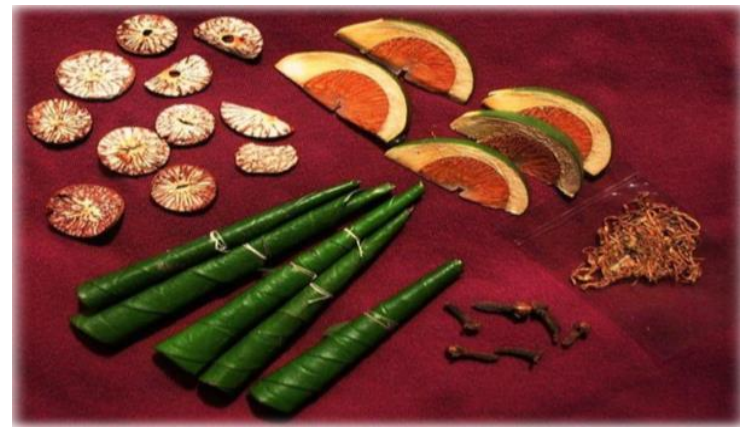

Figure 15. Materials used in preparing paan

\subsection{Sweet Paan or Meetha Paan}

In this type of paan, areca nuts and tobacco are not used, and betel leaves are filled with coconut slices and pieces of dried fruit [3].

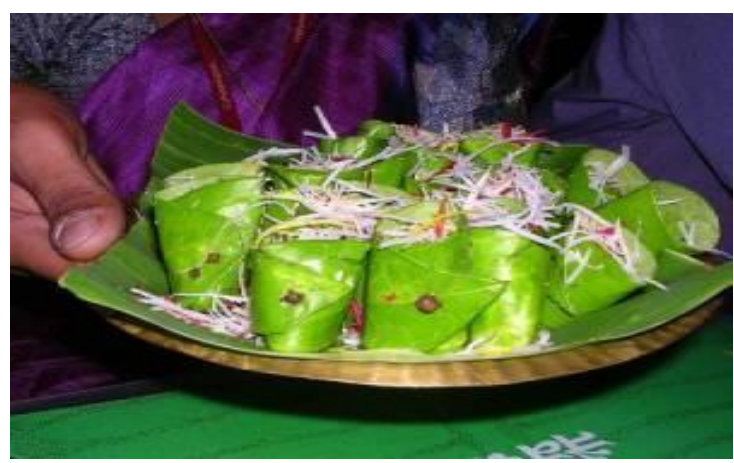

Figure 16. Sweet paan

\subsection{Gutkha}

Gutkha is a combination of broken seeds of Areca catechu, tobacco, ground betel leaves, catechu, lime, sweeteners, and fragrant spices. This combination is in the form of a light brown to white powder and turns red soon after being dissolved in the mouth [23]. Paan Parag is the trade name of a kind of gutkha. No mention is made regarding the tobacco content of paan and gutkha on many of the packages, and millions of adults and children in South and East Asia and in the East use these products, some of which have a chocolate flavor and many are sold as mouth and breath fresheners. People start using these products at an early age because they are cheap and available and have aromatic, pleasant, or sweet flavor; and they are popular, especially among poor children. Various types of paan and gutkha are spat out on doors, walls, or on the ground, and create ugly looking marks on these surfaces that are very difficult to clean.
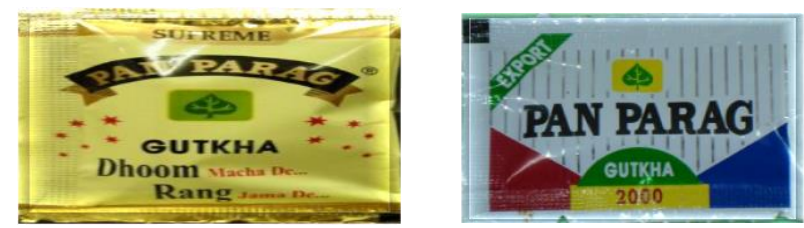

Figure 17. Two types of gutkha

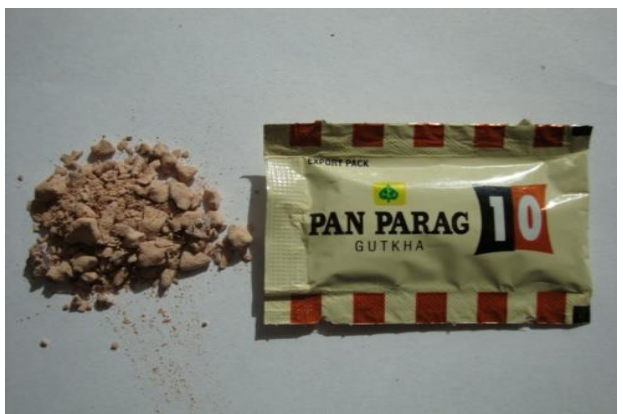

Figure 18. A package of one kind of gutkha (Pan Parag) with the content poured out 
Supari is a widely used product that usually contains ground or sliced Areca catechu nuts together with aromatic seeds or spices and sweeteners and is used especially by women and children [3]. In a global study conducted on tobacco use in adults in 2009-2010, it was concluded that 53.5\% of American Indians used tobacco products. A large number of people in India (66.2\% men and $40 \%$ women) comprising $48.07 \%$ of the total population use tobacco products and gutkha [24].

\subsection{Side Effects of Various Kinds of Paan, Gutkha, and Supari}

- They have carcinogenic effects. The International Agency for Research on Cancer (IARC) considers use of areca nuts and betel leaves one of the factors that cause cancer. People who repeatedly chew betel leaves and areca nuts face a high risk of gum damage and oral cavity, pharynx, esophagus, and stomach cancers. Long-term use of areca nuts alone causes oral submucosal fibrosis, pre-cancerous oral lesions, and squamous cell carcinoma [6] and increases the risk of developing other types of cancer such as liver, prostate, uterus, and lung cancers. Tobacco and lime increase the risk of cancer in those who use paan products [25]. The high incidence of oral cavity cancer in India and Pakistan results from the use of these products.
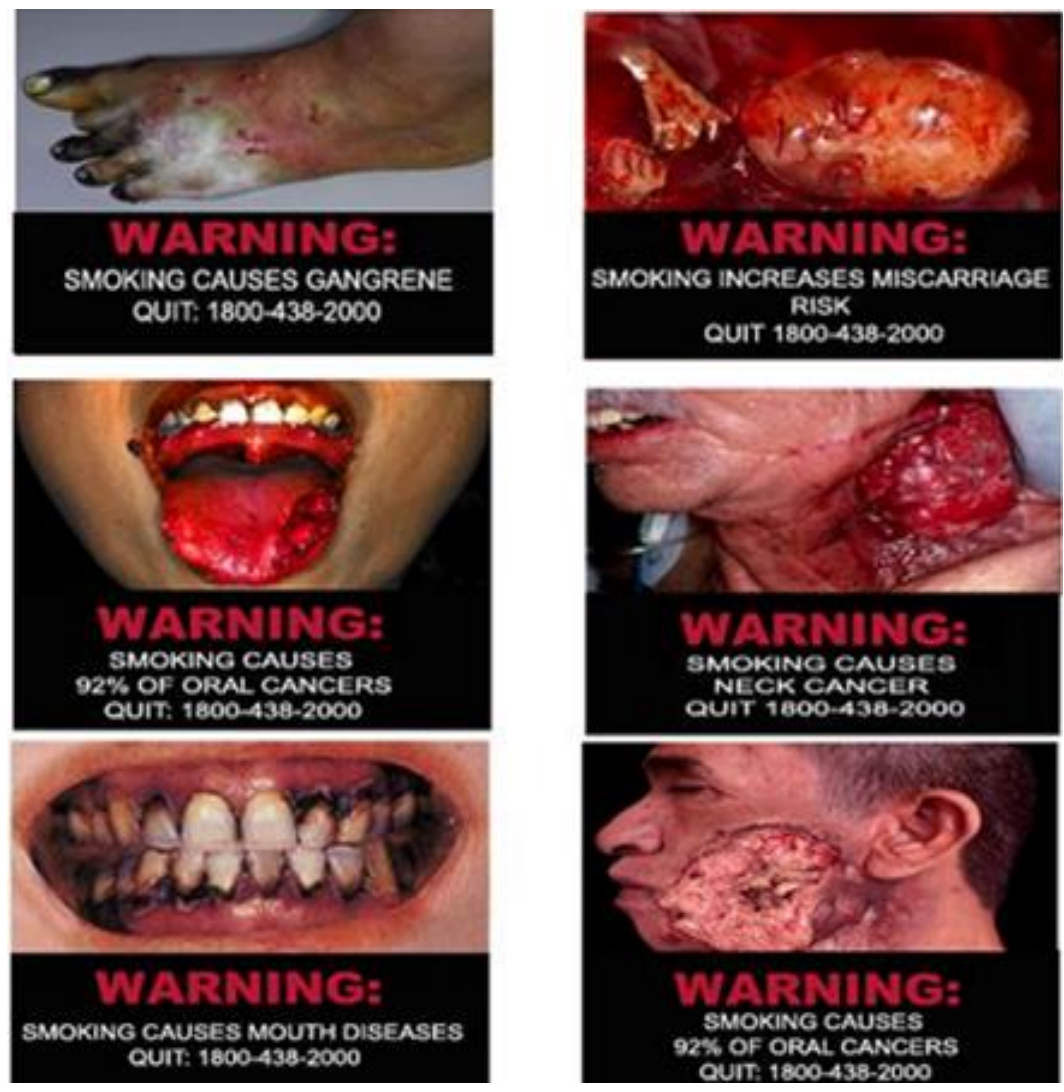

Figure 19. Lesions caused by using various kinds of paan that contain tobacco

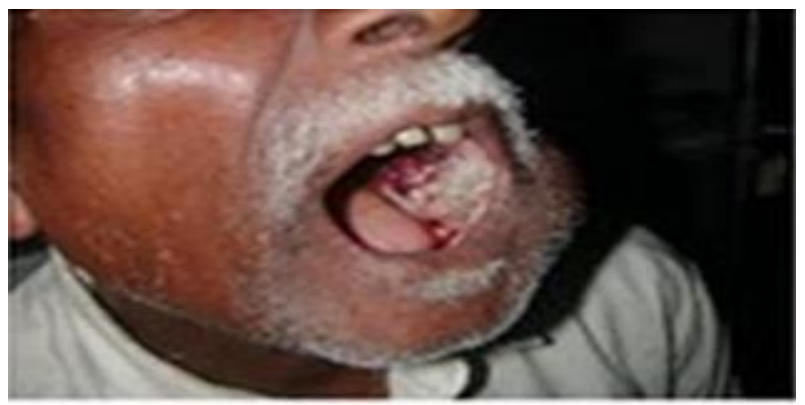

Figure 20. Oral side effects of using gutkha

- The lime in various types of paan and gutkha causes severe corrosion leading to damaged gums and tooth decay (caries), and absorption of nicotine in tobacco, and of arecoline in areca nuts, is greatly enhanced because of the damage inflicted on the mucosa. Moreover, alkalization caused by lime converts nicotine and arecoline to their free base forms and, thereby, increases their absorption. Mucosal irritation by lime is itself carcinogenic [26]. 
- These compounds (especially the arecoline in Areca catechu nuts) increase salivary secretion. Therefore, their users repeatedly spit out oral secretions, which can transmit viral and microbial diseases to other people and pollute the environment.

- Teeth and gums turn yellowish orange and blackish red, will not be easily cleaned by brushing, and will require dental interventions. Spitting out the remains of the substance gives the walls and the ground an unpleasant red color and pollutes the environment [3].

- These compounds are likely to cause poisoning with lead, arsenic, and aflatoxins because they may be polluted with various fungal toxins (aflatoxins) and poisons such as aresenic and lead. Therefore, their use, especially their repeated use, may be accompanied by poisoning.

- As most of them are prepared manually (especially those types that are wrapped in betel leaves) in unhygienic workshops, they may be infected by microbes and viruses during the preparation process, and can also harm the users in this way.

- They intensify asthma symptoms in asthmatics and exacerbate their disease.

- They have diabetogenic effects (cause diabetes) because they raise blood sugar level and increase the risk for type 2 diabetes.

- They cause infertility in users.

- They have weak euphoric and stimulating effects.

- These compounds (especially those containing tobacco and areco nuts) are strongly addictive and, since they contain nicotine, users will suffer from the side effects experience by smokers.

- They suppress appetite.

- They raise blood pressure and heart rate.

- The arecoline in areca nuts has strong cholinergic effects and may cause general symptoms of cholinergic toxicity such as urinary incontinence, increased salivary secretion, diarrhea, watery eyes, sweating, nausea and vomiting, abdominal pains and cramps [26].

- They cause respiratory problems, especially when users are asleep.

- They cause swallowing problems, especially at night when users are asleep, that dry the throat leading to restless sleep.

- They cause confusion, forgetfulness, euphoria, changes in sleep pattern, dizziness, loss of balanced behavior, and madness [26].

\section{Conclusion}

There are various types of paan, Naswar, areca nuts, betel, gutkha, etc., a number of which were referred to in this article, that people use for different reasons such as their euphoric and weakly stimulating effects and low price, and because of their availability and aromatic, pleasant, or sweet flavor. Moreover, we know that they have addictive effects on users, and that Nass or Naswar cause oral cavity cancer, oral submucosal fibrosis, precancerous oral lesions, and squamous cell carcinoma. Furthermore, areca nuts have general cholinergic toxicity, use of betel is related to oral cavity cancer, and various types of paan, gutkha, and supari has side effects including possible poisoning by lead, arsenic, and aflatoxins, is carcinogenic and diabetogenic, causes high blood pressure, and increases heart rate. Therefore, it is necessary to take effective steps and inform people of the effects and side effects of addictive substances so that they can, through taking good care of themselves, keep themselves and their environment healthy. Addiction is a social ill, and we should attempt to take effective measures for preventing and reducing addiction through increasing public knowledge of this social problem.

\section{Acknowledgements}

We hereby express our gratitude to Engineer Mohammad Nasser Hoserini Bejed for cooperating with us in collecting some of the required information regarding paan and Naswar.

\section{Declaration of Competing Interest}

The authors declare that they have no known competing financial interests or personal relationships that could have appeared to influence the work reported in this paper. 


\section{References}

[1] West, R., \& Brown, J. (2013). Theory of addiction. John Wiley \& Sons.

[2] United nations office on drugs and crime. Prevention of drug abuse for those working in the media Group [Guidance]. Tehran.

[3] Mobaraki, Alireza., Mobaraki, Faramarz., Hoseini Bojd, Mohammad Naser., Nakhaei Moghaddam, Tayebeh., Haghani Far, Hosein. (2014). Pan And Nas Meet Addictive Book.

[4] Winn, D. M., Blot, W. J., Shy, C. M., Pickle, L. W., Toledo, A., \& Fraumeni, J. F. (1981). Snuff Dipping and Oral Cancer among Women in the Southern United States. New England Journal of Medicine, 304(13), 745-749. doi:10.1056/nejm198103263041301.

[5] Mobaraki, Alireza. (2009). Pan's cheapest drug. Zahedan University of Medical Science.

[6] Phukan, R. K., Ali, M. S., Chetia, C. K., \& Mahanta, J. (2001). Betel nut and tobacco chewing; potential risk factors of cancer of oesophagus in Assam, India. British Journal of Cancer, 85(5), 661-667. doi:10.1054/bjoc.2001.1920.

[7] Mobaraki, Alireza. (2011). Chancellor for Drug \& Food. Zahedan University of Medical Science.

[8] Ruffle, J. K. (2014). Molecular neurobiology of addiction: what's all the $(\Delta)$ FosB about? The American Journal of Drug and Alcohol Abuse, 40(6), 428-437. doi:10.3109/00952990.2014.933840.

[9] Nestler, E. J. (2013). Cellular basis of memory for addiction. Dialogues in clinical neuroscience, 15(4), 431-443.

[10] Sabha, M., Tanus-Santos, J. E., Toledo, J. C. Y., Cittadino, M., Rocha, J. C., \& Moreno Jr, H. (2000). Transdermal nicotine mimics the smoking - induced endothelial dysfunction. Clinical Pharmacology \& Therapeutics, 68(2), 167-174. doi:10.1067/mcp.2000.108851.

[11] Zhang, S., Day, I., \& Ye, S. (2001). Nicotine induced changes in gene expression by human coronary artery endothelial cells. Atherosclerosis, 154(2), 277-283. doi:10.1016/s0021-9150(00)00475-5.

[12] Hawkins, B. T., Brown, R. C., \& Davis, T. P. (2002). Smoking and ischemic stroke: a role for nicotine? Trends in Pharmacological Sciences, 23(2), 78-82. doi:10.1016/s0165-6147(02)01893-x.

[13] Ferrari, R., Le Novère, N., Picciotto, M. R., Changeux, J. P., \& Zoli, M. (2002). Acute and long-term changes in the mesolimbic dopamine pathway after systemic or local single nicotine injections. European Journal of Neuroscience, 15(11), 1810-1818. doi:10.1046/j.1460-9568.2001.02009.x.

[14] Warnakulasuriya, S. (2002). Areca nut use: an independent risk factor for oral cancer. BMJ, 324(7341), 799-800. doi:10.1136/bmj.324.7341.799.

[15] Gupta, P. C., \& Ray, C. S. (2004). Epidemiology of betel quid usage. Annals-Academy of medicine Singapore, 33, 31-36.

[16] Croucher, R., \& Islam, S. (2002). Socio-economic aspects of areca nut use. Addiction Biology, 7(1), 139-146. doi:10.1080/13556210120091518.

[17] Zain, R. B., Ikeda, N., Gupta, P. C., Warnakulasuriya, S., Wyk, C. W., Shrestha, P., \& Axéll, T. (2007). Oral mucosal lesions associated with betel quid, areca nut and tobacco chewing habits: consensus from a workshop held in Kuala Lumpur, Malaysia, November 25-27, 1996. Journal of Oral Pathology \& Medicine, 28(1), 1-4. doi:10.1111/j.1600-0714.1999.tb01985.x.

[18] Daftary, D. K., Bhonsle, R. B., Murti, R. B., Pindborg, J. J., \& Mehta, F. S. (1980). An oral lichen planus-like lesion in Indian betel-tobacco chewers. European Journal of Oral Sciences, 88(3), 244-249. doi:10.1111/j.1600-0722.1980.tb01221.x.

[19] Jayant, K., Balakrishnan, V., Sanghvi, L. D., \& Jussawalla, D. J. (1977). Quantification of the role of smoking and chewing tobacco in oral, pharyngeal, and oesophageal cancers. British Journal of Cancer, 35(2), 232-235. doi:10.1038/bjc.1977.31.

[20] Ko, Y.-C., Huang, Y.-L., Lee, C.-H., Chen, M.-J., Lin, L.-M., \& Tsai, C.-C. (1995). Betel quid chewing, cigarette smoking and alcohol consumption related to oral cancer in Taiwan. Journal of Oral Pathology and Medicine, 24(10), 450-453. doi:10.1111/j.1600-0714.1995.tb01132.x.

[21] Chang, K. M. (1966). Betel nut chewing and mouth cancer in Taiwan. 2. Observation of the oral mucosa in the betel nut chewer. Taiwan yi xue hui za zhi. Journal of the Formosan Medical Association, 65(2), 79-85.

[22] Cutch and catechu plant origin from the Food and Agriculture (FAO) department of the United Nations. Document repository (accessed on November 2018).

[23] Syrjanen, S. (2003). Human papillomavirus infections and oral tumors. Medical Microbiology and Immunology, 192(3), 123128. doi:10.1007/s00430-002-0173-7.

[24] Use of tobacco products to invite deterrent tax: Modi”. Hindustan Times. 31st October, 2012. (Retrieved on 14 March 2014).

[25] Chiba, I. (2001). Betel Quid chewing. Asian Pacific J. Cancer Preven, 2, 264-269.

[26] Mobaraki, Alireza. (2012). Pan and nass pamphlets. Zahedan University of Medical Science; 2-3. 